\title{
Improvements in the Development of Silicon Nitride Inserts using Hybrid Microwave Energy for Machining Inconel 718
}

\author{
Tasnim Firdaus Ariff ${ }^{1}$, Nur Maizatul Nasyiin Mohamed ${ }^{2}$ \\ Abdulaziz Abdullah Binafif ${ }^{3}$, Ahmad Zahirani Ahmad Azhar ${ }^{4}$ \\ ${ }^{1,2,3,4}$ Department of Manufacturing and Materials Engineering, \\ Faculty of Enginering, International Islamic University Malaysia, \\ Kuala Lumpur, Malaysia
}

\author{
Rubina Bahar ${ }^{5}$ \\ ${ }^{5}$ Department of Mechanical and Materials Engineering, \\ Lee Kong Chian Faculty of Engineering, \\ University Tunku Abdul Rahman, Kajang, Malaysia
}

\author{
A. N. Mustafizul Karim ${ }^{6}$ \\ ${ }^{6}$ Faculty of Science and Engineering, \\ Queensland University of Technology, \\ Brisbane, Australia
}

\author{
A. K. M. Nurul Amin ${ }^{7}$ \\ ${ }^{7}$ Department of Mechanical and Production Engineering, \\ Ahsanullah University of Science and Technology, \\ Bangladesh;
}

\begin{abstract}
Hybrid Microwave (HMW) sintering is becoming popular for heating ceramics, composites, metals and alloys. It is becoming a trendy research due to its capabilities in saving time, energy and money, increasing efficiency and productivity, improving mechanical and structural properties. Silicon Nitride $\left(\mathrm{Si}_{3} \mathrm{~N}_{4}\right)$ is widely used as a cutting insert for machining cast iron, hard steel and nickel based alloys. It is mass produced by traditional powder technology. This research aims to increase the tool life of the Silicon Nitride inserts by enhancing the mechanical and structural properties by using Hot Isostatic Pressing (HIP) at $1800^{\circ} \mathrm{C}$ and followed by hybrid microwave (HMW) post-sintering at $200^{\circ} \mathrm{C}$ for 10 minutes with the aid of Silicon Carbide powder as susceptor. Three different compositions $\left(88 \%, 90 \%\right.$ and $\left.92 \% \mathrm{Si}_{3} \mathrm{~N}_{4}\right)$ were synthesized in order to find the optimum composition using these techniques. Mechanical and structural properties were analyzed. The combination of $\mathrm{HIP}+\mathrm{HMW}$ post sintering for just 10 minutes significantly enhanced the density (93-97\% TD), hardness (18$22 \%)$, compressive strength (2-4\%) and produced finer uniform grains particularly for $88 \%$ and $90 \% \mathrm{Si}_{3} \mathrm{~N}_{4}$ when compared with HIP samples without any post sintering effect. Hence, the $88 \%$ and $90 \% \mathrm{Si}_{3} \mathrm{~N}_{4}$ compositions produced by the combination of HIP+HMW post sintering are potentially suitable candidates for machining hard materials such as Inconel 718.
\end{abstract}

Keywords-Silicon carbide; hybrid microwave post sintering; hot isostatic pressing; enhanced densification; improved mechanical properties; Inconel 718

\section{INTRODUCTION}

Ceramic inserts are widely used in the field of high speed machining of hard materials. Silicon nitride $\left(\mathrm{Si}_{3} \mathrm{~N}_{4}\right)$ is an example of an insert that has a unique set of outstanding properties such as high hot hardness, high wear resistance, high fracture toughness, improved oxidation and chemical resistance [1]. Ceramic inserts are generally produced by traditional particulate processing techniques.
Hybrid microwave energy has gained popularity in the world of particulate processing of ceramic materials. Charmond et al. investigated on the densification and microstructure changes of $2 \mathrm{~mol} \%$ yttria-stabilized zirconia nano powder and concluded that hybrid heating produced homogeneous microstructures whereas direct microwave heating led to rather heterogeneous microstructures due to thermal gradients [2]. Thauri et al. analyzed on the mechanical properties of titanium carbide (TiC) in hybrid microwave sintering; and found out that samples with improved density and hardness were produced by hybrid microwave sintering in a shorter processing time which is $93 \%$ faster than conventional sintering and $50 \%$ faster than Hot Isostatic Pressing [3]. ITO ceramics generally are difficult to achieve full densities using conventional heating because of the volatilization property of both indium oxide $\left(\mathrm{In}_{2} \mathrm{O}_{3}\right)$ and tin oxide $\left(\mathrm{SnO}_{2}\right)$ at high temperatures. However, Chen et al. managed to achieve 99\% of theoretical density by doping it with Zinc Oxide and sintering it using hybrid microwave energy in just 25 minutes [4].

Hybrid microwave heating is a function of the material being processed, and there is almost $100 \%$ conversion of electromagnetic energy into heat, largely within the sample itself, unlike conventional heating, where there are significant thermal energy losses [5]. Hybrid microwave heating is an improvement process from the direct microwave heating. It provides a two directional heating process with the aid of a susceptor. Susceptors must have good thermal shock resistance and be able to sustain high temperature and provide rapid heating to the sample [6](Oghbaei and Mirzaee, 2010). The use of susceptor with microwave energy results in uniform volumetric heating; from inside to outside as well as from outside to inside. Furthermore, it also contributes to the 
rapid heating process. In addition, the rapid initial heating via susceptors becomes the key factor to execute the energy efficient microwave processing for the poorly microwave absorbing materials [7].

Microwave processing for sintering or post-sintering ceramics has advantages such as increased heating rates, uniform heating, reduced cost and improved mechanical and structural properties compared to conventional methods [811] (Huang et al., 2009; Ariff et al., 2014; Oakley, 2014; Xu, 2017). Most of the researches pertaining to microwave sintering of $\mathrm{Si}_{3} \mathrm{~N}_{4}$ in general focus on the comparison of microwave with conventional heating in terms of its mechanical and structural properties. The actual performance is rarely seen in action.

Machining extremely hard materials such as tungsten and nickel alloys contribute to a higher wear rate and shortened tool life which contributes to an increased tooling cost. Full HMW sintering using an industrial microwave furnace has proven to reap outstanding properties at lower temperatures and faster processing times when compared with conventional sintering [12]. However, high investments may be required in purchasing an industrial microwave furnace (with higher heating capability) which does not make the process so appealing to industries. Therefore, this research is intended to cater for cheaper options by simply using domestic microwave oven and apply post sintering methods which can eventually enhance properties of the inserts and increase tool life. Hence, this research aims in determining a suitable composition of $\mathrm{Si}_{3} \mathrm{~N}_{4}$ inserts that can be produced by Hot Isostatic Pressing (HIP) and followed by post sintering at $200{ }^{\circ} \mathrm{C}$ for only 10 minutes using Hybrid Microwave (HMW) energy. The outcome of this research is intended to produce inserts that can be used for machining hard materials; particularly Inconel 718.

\section{EXPERIMENTAL PROCEDURE}

\section{A. Preparation of samples}

Three different compositions of Silicon Nitride powders were used in this experiment as shown in Table I to produce round cutting tool inserts. The powder consists of Silicon Nitride $\left(\mathrm{Si}_{3} \mathrm{~N}_{4}\right)$, Yttrium Oxide $\left(\mathrm{Y}_{2} \mathrm{O}_{3}\right)$, Magnesium Oxide $(\mathrm{MgO})$, Aluminium Oxide $\left(\mathrm{Al}_{2} \mathrm{O}_{3}\right)$ and Silicon Dioxide $\left(\mathrm{SiO}_{2}\right)$. These powders (Alfa Aesar) with the size of $0.5 \mu \mathrm{m}$ were weighed using the digital weighing scale (Sartorius CP224S) and then mixed in a planetary ball mill (FRITSCH 5) for 6 hours at $150 \mathrm{rpm}$ with the aid of the steel balls in the ratio of number of balls to powder weight 1:5.

TABLE I. COMPOSITIONS OF SILICON NITRIDE INSERTS

\begin{tabular}{|c|c|c|c|c|c|}
\hline Sample & $\begin{array}{c}\mathrm{Si}_{3} \mathrm{~N}_{4} \\
(\%)\end{array}$ & $\begin{array}{c}\mathrm{Y}_{2} \mathrm{O}_{3} \\
(\%)\end{array}$ & $\begin{array}{c}\mathrm{MgO} \\
(\%)\end{array}$ & $\begin{array}{c}\mathrm{Al}_{2} \mathrm{O}_{3} \\
(\%)\end{array}$ & $\begin{array}{c}\mathrm{SiO}_{2} \\
(\%)\end{array}$ \\
\hline 1 & 88 & 5.5 & 2.5 & 2 & 2 \\
\hline 2 & 90 & 4 & 2.5 & 2 & 1.5 \\
\hline 3 & 92 & 2.5 & 2.5 & 2 & 1 \\
\hline
\end{tabular}

The powders were compacted using cold press; manual pellet pressing machine (MP-15T) with a load of $150 \mathrm{kN}$ and a holding time of 5 minutes for each sample. 18 samples with average diameter of $13.64 \mathrm{~mm}$ and average thickness of 5.33 $\mathrm{mm}$ were produced for each composition.

\section{B. Sintering Process}

The green samples were placed into the HIP furnace (AIP6-30H) at $1800^{\circ} \mathrm{C}$ at a heating rate of $5^{\circ} \mathrm{C} / \mathrm{min}$ with 1 hour holding time. Argon gas was used in this HIP process. Then, 9 samples from the HIP were taken for further postsintering using $\mathrm{HMW}$. The $\mathrm{Si}_{3} \mathrm{~N}_{4}$ samples were placed vertically inside a small alumina crucible with a diameter of $30 \mathrm{~mm}$ at the opening and covered with a lid. This is to ensure that the heating is uniform all around the insert. The small crucible was then placed inside a larger crucible with a diameter of $65 \mathrm{~mm}$ at the opening and submerged inside 50 $\mathrm{cm}^{3}$ ( $300 \mathrm{mesh}$ ) of Silicon Carbide (SiC) powder (Alfa Aesar) which functions as a susceptor to aid in rapid hybrid microwave heating (Fig. 1). The larger crucible is covered with a lid as well. The crucibles were later placed inside the domestic microwave oven (Panasonic NN-CD997S) with a magnetron operating frequency of $2.45 \mathrm{GHz}$ for 10 minutes at $200^{\circ} \mathrm{C}$

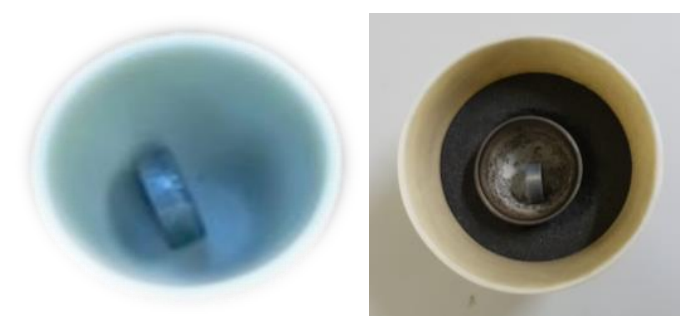

Fig. 1: Setup of the $\mathrm{Si}_{3} \mathrm{~N}_{4}$ sample inside the alumina crucible for HMW heating

\section{Mechanical Testing}

The dimensions of the $\mathrm{Si}_{3} \mathrm{~N}_{4}$ samples were recorded; the physical appearance and shrinkage were analyzed. The densities of the $\mathrm{Si}_{3} \mathrm{~N}_{4}$ samples from each composition were measured using Densimeter (OK-300). Then, hardness test was performed using Vickers Micro-hardness Tester (401MVA), followed by compression test to determine the compressive strength and its corresponding tensile strength of the $\mathrm{Si}_{3} \mathrm{~N}_{4}$ inserts using Universal Testing Machine (INSTRON 3367) with a tonnage of $100 \mathrm{kN}$. The results were compared with the commercial tool (Sandvik Coromant RNGN 6060) which can be used to machine hard materials, such as Inconel 718.

\section{Scanning Electron Microscope}

The $\mathrm{Si}_{3} \mathrm{~N}_{4}$ samples were polished with the aid of Micro Polish Alumina $(0.3 \mu \mathrm{m})$ on a polishing machine (PRESI MECAPOL P230). Etching was done using phosphoric acid (H3PO4) for 100-120 seconds at room temperature. A Sputter Coater (SC7620) was used to coat the samples in order to make it conductive. Micro structural analysis was performed by using the Scanning Electron Microscope (JEOL JSM5600). 


\section{RESULTS AND DISCUSSION}

\section{A. Physical Appearance}

The $\mathrm{Si}_{3} \mathrm{~N}_{4}$ samples before and after sintering can be seen in Fig. 2. It is clearly obvious that the samples have undergone shrinkage. The three compositions; $88 \mathrm{Si}_{3} \mathrm{~N}_{4}, 90$ $\mathrm{Si}_{3} \mathrm{~N}_{4}$ and $92 \mathrm{Si}_{3} \mathrm{~N}_{4}$ have very similar shrinkage values for both HIP (-8\%) and HIP+HMW (-10\%). In addition, change in color from the green condition (light grey) to after HIP (dark grey) and after HMW (grey) was observed.

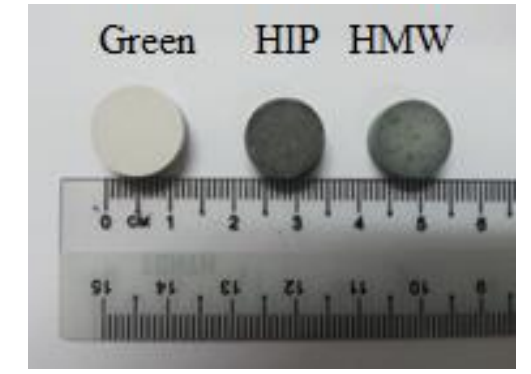

Fig.2: Physical appearance of the $\mathrm{Si}_{3} \mathrm{~N}_{4}$ samples

\section{B. Mechanical Properties}

The densities for the three $\mathrm{Si}_{3} \mathrm{~N}_{4}$ compositions are shown in Table II. Results show that HIP alone produced samples with $93 \%, 92 \%$ and $90 \%$ of theoretical density (TD) for 88, 90 and $92 \mathrm{wt} \% \mathrm{Si}_{3} \mathrm{~N}_{4}$ respectively. However, after post sintering with $\mathrm{HMW}$ for only 10 minutes at $200^{\circ} \mathrm{C}$, the densities significantly increased to $97 \% \mathrm{TD}$, 96.6\%TD and 93\%TD. Certain amounts of additives such as $\mathrm{Y}_{2} \mathrm{O}_{3}, \mathrm{MgO}$ and $\mathrm{Al}_{2} \mathrm{O}_{3}$ were added to produce a glassy inter granular phase during sintering in order to achieve proper densification of the $\mathrm{Si}_{3} \mathrm{~N}_{4}$ samples which can enhance metal cutting performance.

TABLE II. DENSITY AND HARDNESS OF $\mathrm{SI}_{3} \mathrm{~N}_{4}$ SAMPLES

\begin{tabular}{|c|c|c|c|c|}
\hline Sample & \multicolumn{2}{|c|}{ Density $\left(\mathrm{g} / \mathrm{cm}^{3}\right)$} & \multicolumn{2}{c|}{ Hardness (HV) } \\
\hline & HIP & $\begin{array}{c}\text { HIP+ } \\
\text { HMW }\end{array}$ & HIP & $\begin{array}{c}\text { HIP+ } \\
\text { HMW }\end{array}$ \\
\hline $88 \mathrm{Si}_{3} \mathrm{~N}_{4}$ & 3.031 & 3.158 & 1124 & 1438 \\
\hline $90 \mathrm{Si}_{3} \mathrm{~N}_{4}$ & 2.997 & 3.136 & 1099 & 1396 \\
\hline $92 \mathrm{Si}_{3} \mathrm{~N}_{4}$ & 2.911 & 3.023 & 1002 & 1219 \\
\hline RNGN 6060 & \multicolumn{2}{|c|}{3.219} & \multicolumn{2}{c|}{1454} \\
\hline
\end{tabular}

Meanwhile, the hardness value for $88 \mathrm{Si}_{3} \mathrm{~N}_{4}$ is the highest $(1438 \mathrm{HV})$, followed by $90 \mathrm{Si}_{3} \mathrm{~N}_{4}(1396 \mathrm{HV})$ and $92 \mathrm{Si}_{3} \mathrm{~N}_{4}$ (1219 HV). This conforms to the findings with the density values of the samples where hardness increases as density increases. The density and hardness of HIP+HMW for both $88 \mathrm{Si}_{3} \mathrm{~N}_{4}$ and $90 \mathrm{Si}_{3} \mathrm{~N}_{4}$ are quite close to one another because of the weight percentage of $\mathrm{MgO}(2.5 \%)$ and $\mathrm{Al}_{2} \mathrm{O}_{3}(2 \%)$ that remained unchanged in both compositions. The $88 \mathrm{Si}_{3} \mathrm{~N}_{4}$ and $90 \mathrm{Si}_{3} \mathrm{~N}_{4}$ (HIP+HMW) samples have the density and hardness values which are quite similar to the commercial insert (RNGN 6060).

The compressive strength values for these three compositions of $\mathrm{Si}_{3} \mathrm{~N}_{4}$ samples are shown in Fig. 3. The corresponding tensile strength for each sample was calculated using (1) which is commonly used for ceramics and brittle materials in disk shape (Kalpakjian and Schmid, 2014),

$$
\sigma=2 P / \pi d t
$$

where $\sigma$ is the tensile strength (MPa), $P$ is the load applied along the centerline of the disk $(\mathrm{N}), d$ is the diameter of the sample (mm) and $t$ is the thickness (mm).

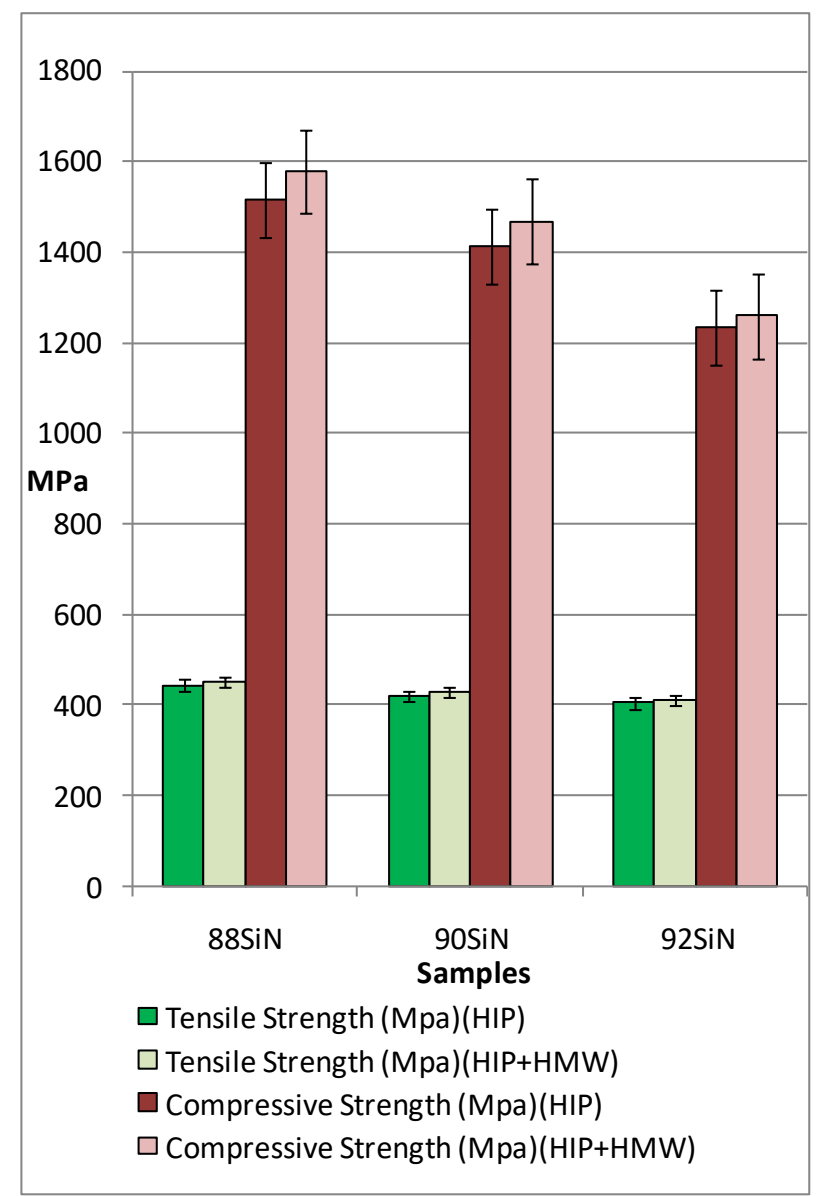

Fig. 3: Mechanical properties of $\mathrm{Si}_{3} \mathrm{~N}_{4}$ samples

Tensile strengths are generally low for ceramics due to its natural characteristics. All three compositions possessed almost similar tensile strength values in the range of 404 $452 \mathrm{MPa}$; the highest value was found in $88 \mathrm{Si}_{3} \mathrm{~N}_{4}$ (HIP $+\mathrm{HMW}$ ) while the lowest value in $92 \mathrm{Si}_{3} \mathrm{~N}_{4}$ (HIP). Ceramics are stronger in compression; which justifies the significantly larger compressive strength values for all three compositions of the $\mathrm{Si}_{3} \mathrm{~N}_{4}$ samples. Larger compressive strengths were found in HIP+HMW samples when compared with HIP alone. $88 \mathrm{Si}_{3} \mathrm{~N}_{4}$ produced the largest compressive strength (1578 MPa), followed by $90 \mathrm{Si}_{3} \mathrm{~N}_{4}(1469 \mathrm{MPa})$ and $92 \mathrm{Si}_{3} \mathrm{~N}_{4}$ (1260 MPa). Post sintering for 10 minutes using HMW resulted in an increase in compressive strength by $4.2 \%$, $3.9 \%$, and $2.1 \%$ for the $88 \mathrm{Si}_{3} \mathrm{~N}_{4}, 90 \mathrm{Si}_{3} \mathrm{~N}_{4}$ and $92 \mathrm{Si}_{3} \mathrm{~N}_{4}$ respectively.

Hybrid microwave post sintering provides efficient internal volumetric heating. The electromagnetic energy 
which is converted into heat, is penetrated directly into the $\mathrm{Si}_{3} \mathrm{~N}_{4}$ samples. The $\mathrm{SiC}$ powders which act as a susceptor with good microwave absorption characteristics, help improve heating rate. Heat is generated uniformly throughout the $\mathrm{Si}_{3} \mathrm{~N}_{4}$ sample as a result from the energy transfer.

\section{Micro Structural Analysis}

The SEM images for the $\mathrm{Si}_{3} \mathrm{~N}_{4}$ samples are shown in Fig.4. $88 \mathrm{Si}_{3} \mathrm{~N}_{4}$ appeared to be very dense with uniform fine grained microstructure for both HIP and HIP+HMW. Meanwhile, for the $90 \mathrm{Si}_{3} \mathrm{~N}_{4}$ (HIP), uniformly distributed small sized pores were visible and the HIP+HMW sample produced uniform grain size. Larger sized pores were noticeable in the $92 \mathrm{Si}_{3} \mathrm{~N}_{4}$ (HIP) and larger grain size in $92 \mathrm{Si}_{3} \mathrm{~N}_{4}(\mathrm{HIP}+\mathrm{HMW})$. Better densification and improved microstructure are observed in the $88 \mathrm{Si}_{3} \mathrm{~N}_{4}$ and $90 \mathrm{Si}_{3} \mathrm{~N}_{4}$.

HIP

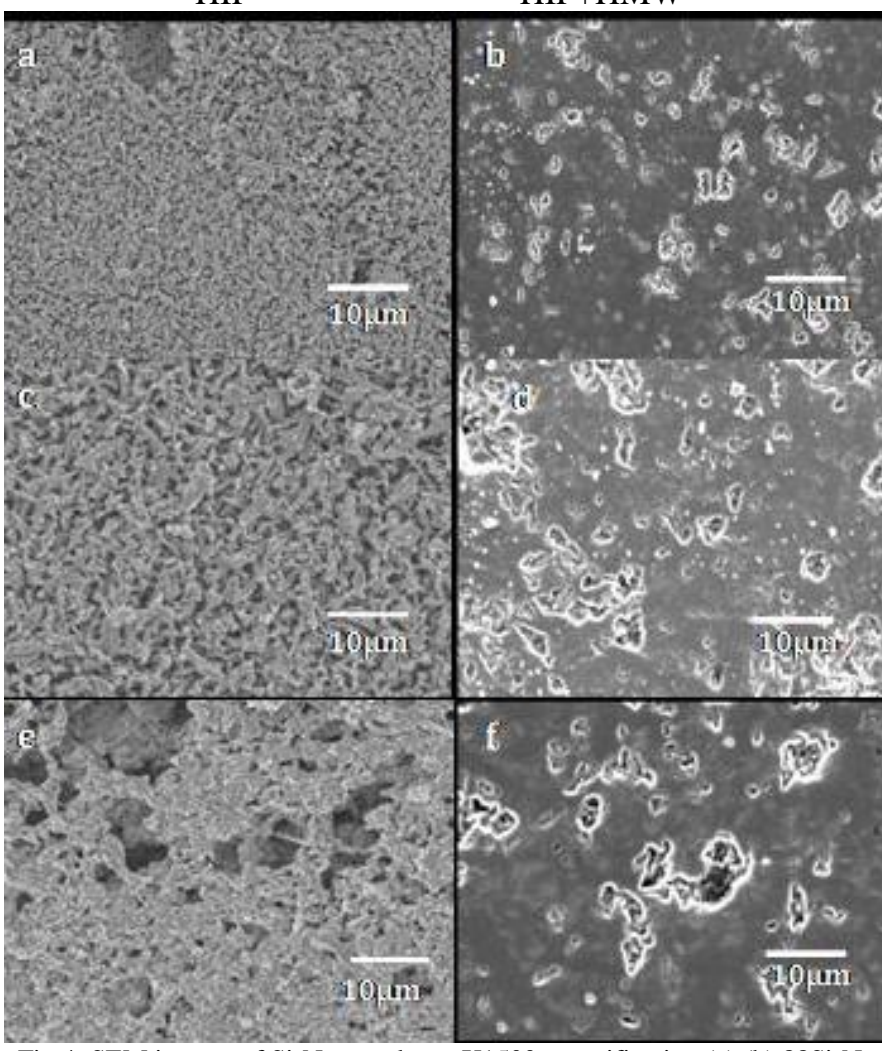

Fig 4: SEM images of $\mathrm{Si}_{3} \mathrm{~N}_{4}$ samples at X1500 magnification (a),(b) $88 \mathrm{Si}_{3} \mathrm{~N}_{4}$ (c), (d) $90 \mathrm{Si}_{3} \mathrm{~N}_{4}$ (e),(f) $92 \mathrm{Si}_{3} \mathrm{~N}_{4}$

\section{CONCLUSIONS}

Hybrid microwave post sintering of $\mathrm{Si}_{3} \mathrm{~N}_{4}$ samples for only 10 minutes at $200^{\circ} \mathrm{C}$ is effective in producing samples with improved mechanical properties (density, hardness and strength) and structural characteristics (uniform grain size and smaller pores). Based on the experimental results obtained, out of the three compositions $(88 \%, 90 \%$ and $92 \%$ $\mathrm{Si}_{3} \mathrm{~N}_{4}$ ), the most suitable compositions of $\mathrm{Si}_{3} \mathrm{~N}_{4}$ sample using HIP+ HMW post sintering technique that can be used as good candidates for machining hard materials such as Inconel 718 are $88 \mathrm{Si}_{3} \mathrm{~N}_{4} \quad 5.5 \mathrm{Y}_{2} \mathrm{O}_{3} \quad 2.5 \mathrm{MgO} \quad 2 \mathrm{Al}_{2} \mathrm{O}_{3} \quad 2 \mathrm{SiO}_{2}$ and $90 \mathrm{Si}_{3} \mathrm{~N}_{4}$ $4 \mathrm{Y}_{2} \mathrm{O}_{3} 2.5 \mathrm{MgO} 2 \mathrm{Al}_{2} \mathrm{O}_{3} 1.5 \mathrm{SiO}_{2}$.

\section{ACKNOWLEDGMENT}

A great appreciation goes to the Ministry of Higher Education for funding this project through the Fundamental Research Grant Scheme (FRGS 14-157-0398) and to all those who have contributed into the experimental work of this research.

\section{REFERENCES}

[1] S. Kalpakjian and S.R. Schmid, Manufacturing Engineering and Technology, 7th ed., Pearson Education South Asia Pte. Ltd., 2014 pp. 65-66.

[2] S. Charmond, C.P. Carry, and D. Bouvard, "Densification and microstructure Evolution of Y-Tetragonal Zirconia Polycrysta Powder During Direct and Hybrid Microwave Sintering in a Single Mode Cavity". J. Eur. Ceram. Soc., vol.30, no.6, pp. 1211-122, 2010

[3] S.H. Thauri, T.F. Ariff, and A.N.M. Karim, "Study of TiC Cutting Tool Insert Using Microwave Synthesis”. Appl. Mech. Mater., vol. 52, pp. 2116-2121, 2011

[4] D. Chen, C. Jiang, H. Sun, B. Feng, X. Lu X, J. Weng, and J. Wang, "Sintering Study of ITO using ZNO-Doped and Microwave Hybric Sintering Approach", J. Asian Ceram. Soc., vol. 2, no. 1, pp. 57-63, 2014

[5] D. Agrawal, "Microwave Sintering of Ceramic, Composites an Metallic Materials, and Melting of Glasses", Trans. Ind. Ceram. Soc., vol. 65, no.3, pp. 129-144, 2006.

[6] Oghbaei, M and Mirzaee, O "Microwave versus Conventional Sintering: A Review of Fundamentals, Advantages and Applications", ChemInform, vol. 41, April 2010.

[7] M. Bhattacharya and T. Basak, "A Review on the Suscepto Assisted Microwave Processing of Materials", Energy, vol. 97, pp 306-338, 2016

[8] Z. Huang, M. Gotoh, and Y. Hirose, "Improving Sinterability of Ceramics Using Hybrid Microwave Heating", J. Mater. Process. Technol., vol. 209, pp. 2446-2452, 2009.

[9] T.F. Ariff, H.I.Ibrahim, N.S. Roselley, M. Iqbal, I. Hilmy, an Suryanto, "Enhancing Tool life of Silicon Nitride Inserts Via Hybrid Microwave Post Sintering”. Aust. J. Basic Appl. Sci., vol.8, no. 15, pp. 80-85, 2014.

[10] S. Oakley, "Studies on Effects of Machining at High Speed on the Mechanical Properties of Silicon Nitride in Hybrid Microwave Process”, J. Miner. Mater. Charact. Eng., vol. 3, pp. 142-153, 2014.

[11] W. Xu, Z. Yin, J. Yuan, Z. Wang, and Y. Fang, "Effects Of Sintering Additives On Mechanical Properties And Microstructure Of $\mathrm{Si}_{3} \mathrm{~N}_{4}$ Ceramics By Microwave Sintering". Mater. Sci. Eng. A., vol. 684: pp. 127-134, 2017

[12] T.N. Tiegs, J.O. Kiggans, and H.D. Kimrey, "Microwave Sintering of Silicon Nitride", Ceram. Eng. Sci. Proc., vol.12, pp. 1981-1992, March 2008 